\title{
The effects of aerobic fatigue on jump shot kinematics in team handball players
}

\author{
Hillary A. Plummer, Gretchen D. Oliver \\ School of Kinesiology, Auburn University, Auburn, USA \\ Correspondence: Gretchen D. Oliver, PhD. Address: School of kinesiology, Auburn University, 301 Wire Rd. Auburn, AL \\ 36832, USA. Email: goliver@auburn.edu
}

Received: July 20, 2015

DOI : $10.5430 /$ jbei.v2n1p65

Accepted: September 20, 2015

URL: http://dx.doi.org/10.5430/jbei.v2n1p65

Online Published: October 8, 2015

\section{Abstract}

Background: Aerobic fatigue from running may contribute to altered kinematics and as a result the possibility of injury exists. The purpose of this study was to examine the effects of aerobic fatigue on jump shot kinematics in team handball players.

Methods: Ten male team handball players $(23.60 \pm 3.06$ years; $184.68 \pm 8.78 \mathrm{~cm} ; 84.76 \pm 9.23 \mathrm{~kg})$ volunteered. An electromagnetic tracking system was used to examine the kinematics of the jump shot prior to and following aerobic fatigue. The fatiguing protocol consisted of running to exhaustion at a speed that corresponded with $80 \%$ of their heart rate maximum.

Results: Significant pelvis and trunk kinematic differences were observed following the aerobic fatigue protocol. For both the trunk $\left(\mathrm{F}_{6,54}=5.10 ; P<.01\right.$; power $\left.=0.99\right)$ and pelvis $\left(\mathrm{F}_{3,27}=14.47 ; P<.01\right.$; power $\left.=1.00\right)$ a three-way interaction of event $\mathrm{x}$ time $\mathrm{x}$ direction was observed. At foot contact, significant differences were observed for pelvis lateral flexion, pelvis rotation, and trunk flexion. The pelvis was positioned with greater lateral flexion to the contralateral side $\left(-1.25^{\circ} \pm\right.$ $3.41^{\circ}$ to $\left.-3.39^{\circ} \pm 4.14^{\circ}\right)$ and increased contralateral pelvis rotation was observed $\left(-43.07^{\circ} \pm 12.92^{\circ}\right.$ to $\left.-50.79^{\circ} \pm 12.26^{\circ}\right)$. Pelvis lateral flexion towards the contralateral side was also significantly greater at ball release following fatigue $\left(-21.90^{\circ}\right.$ $\pm 5.99^{\circ}$ to $-25.55^{\circ} \pm 7.79^{\circ}$ ). Trunk rotation significantly increased from $-6.80^{\circ} \pm 10.07^{\circ}$ to $-12.55^{\circ} \pm 10.97^{\circ}$ at maximum external rotation following fatigue.

Conclusion: Altered mechanics were observed at the pelvis and trunk and these alterations may contribute to injury in team handball players as a player reaches fatigue.

\section{Key words}

Biomechanics, Kinetic chain, Throwing, Upper extremity, Sports

\section{Introduction}

Fatigue is a complex and multi-faceted physiological response that is difficult to quantify ${ }^{[1]}$. Irrespective of the difficulty of quantifying fatigue, fatigue has been widely studied in the literature. The term fatigue has been defined as any reduction 
in maximal force generating capacity, irrespective of the force required for a specified task ${ }^{[1-8]}$. Force production, movement coordination, motor control precision, muscle reaction times and proprioception have all been reported to be negatively affected by fatigue ${ }^{[1-3]}$. These factors that are altered can be considered decrements in performance that may also contribute to the risk of injury through the inability to attenuate force and stabilize a joint ${ }^{[1,9]}$. While the effects of fatigue have been widely examined in the literature, data are lacking on the sport of team handball. With the paucity of available research regarding fatigue in team handball, it is difficult to understand not only the biomechanical alterations but also the injury patterns associated with fatigue in this high demanding sport.

The sport of team handball is unique in that it requires a combination of dynamic movements throughout the course of a game. These movements include running, jumping, landing, throwing, catching, and cutting maneuvers. The mechanisms causing these movements to be altered once a player reaches fatigue have yet to be examined, however, the effects of fatigue on both static and dynamic activities, focusing primarily on the lower extremity, have been extensively examined in other sports ${ }^{[2,3,10-16]}$. While little research has aimed to examine kinematic differences in upper extremity movement patterns following fatigue, the literature available on the lower extremity has identified potential flawed mechanics that increase the risk of injury ${ }^{[2,3,10-16]}$. For instance, movements that involve sudden change of direction, landing from a jump, and rapid stops are all non-contact mechanisms of injury that are greatly affected by lower extremity kinematics. Because these movements have previously been identified as common injury mechanisms great effort has been taken to understand how lower extremity kinematics are affected by fatigue, yet the application of the same methodology to the upper extremity has gone mostly unconsidered. Based on the results of these previous studies of lower extremity dominant sports, it is evident that kinematic alterations occur following fatigue. Thus it is speculated that kinematic alterations during upper extremity dynamic movements, such as throwing, may place a joint in a compromised position that increases the risk of injury.

The sport of team handball consists of two, 30-minute half's of play in which players must run the length of the court repeatedly. Because of the demands of continued running throughout the course of competition it is important to examine the effects of the aerobic fatigue on shooting mechanics. Aerobic fatigue from running may contribute to altered upper extremity kinematics and as a result of these altered kinematics the possibility of injury exists. Therefore, the purpose of this study was to examine the effects of aerobic fatigue on jump shot kinematics in team handball players. There are little data available examining the effects of fatigue on upper extremity movement patterns, thus the results of this study attempt to fill the research void on the role of fatigue on throwing mechanics. Gaining an understanding on how the aerobic demands of running effect jump shot mechanics will allow for the development of improved training protocols for team handball players. It was hypothesized that kinematic differences at the pelvis, trunk, shoulder and elbow during the jump shot would be present following aerobic fatigue.

\section{Methods}

\subsection{Participants}

A power analysis was performed for this study and in order to have a power of 0.80 and effect size $F$ of 0.50 at $\alpha=0.05$ only 10 participants were needed. Pilot data were used to select the effect size $\mathrm{F}$ for the power analysis (unpublished data). Ten male team handball players ( $23.60 \pm 3.06$ years; $184.68 \pm 8.78 \mathrm{~cm} ; 84.76 \pm 9.23 \mathrm{~kg}$ ) volunteered to participate in this study. The University's Institutional Review Board approved all testing protocols. Prior to data collection all testing procedures were explained to each participant and informed consent was obtained.

\subsection{Procedures}

The MotionMonitor $^{\mathrm{TM}}$ (Innovative Sports Training, Chicago, IL) synced with an electromagnetic tracking system (Track Star, Ascension Technologies Inc., Burlington, VT) was used to collect data. The electromagnetic tracking system has 
been validated for tracking humeral movements, producing trial-by trial interclass correlation coefficients for axial humerus rotation in both loaded and non-loaded condition in excess of $0.96^{[17]}$. With electromagnetic tracking systems, field distortion has been shown to be the cause of error in excess of $5^{\circ}$ at a distance of $2 \mathrm{~m}$ from an extended range transmitter ${ }^{[18]}$, but increases in instrumental sensitivity have reduced this error to near $10^{\circ}$ prior to system calibration and $2^{\circ}$ following system calibration ${ }^{[18-20]}$. Thus prior to data collection, the current system was calibrated using previously established techniques ${ }^{[18-20]}$. Following calibration, magnitude of error in determining the position and orientation of the electromagnetic sensors within the calibrated world axes system was less than $0.01 \mathrm{~m}$ and $3^{\circ}$ respectively. The collection rate for all kinematic data describing the position and orientation of electromagnetic sensors was set at $100 \mathrm{~Hz}^{[21-25]}$. Raw data were independently filtered along each global axis using a 4th order Butterworth filter with a cutoff frequency of $13.4 \mathrm{~Hz}^{[21-25]}$. Force plate data were sampled at a rate of $1,000 \mathrm{~Hz}$.

Figure 1. Electromagnetic sensor placement

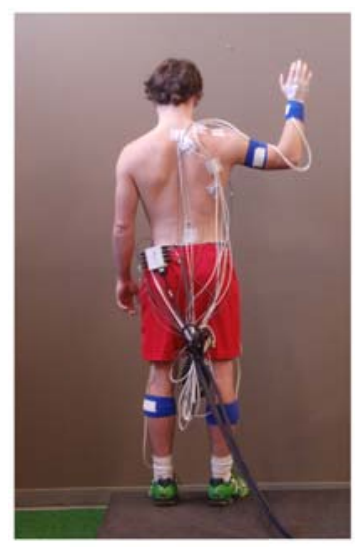

Participants had a series of 11 electromagnetic sensors (Track Star, Ascension Technologies Inc., Burlington, VT) attached at the following locations (see Figure 1): 1) seventh cervical vertebra (C7) spinous process; 2) pelvis at sacral vertebrae 1 (S1); 3) deltoid tuberosity of the throwing arm humerus; 4) throwing arm wrist, between the radial and ulnar styloid processes; 5) acromioclavicular joint of the throwing arm; 6) third metacarpal of the throwing hand; 7-8) bilateral shank centered between the head of the fibula and lateral malleolus; 9-10) bilateral lateral aspect of the femur ${ }^{[21,23,26,27]}$ and 11) third metatarsal of the stride leg foot (see Figure 1). Student researchers, who were trained in the application techniques, applied the sensors. Sensors were affixed to the skin using PowerFlex cohesive tape (Andover Healthcare, Inc., Salisbury, MA) to ensure the sensors remained secure throughout testing. Following the application of the sensors, an additional sensor was attached to a stylus and used for digitization following previously established guidelines ${ }^{[21,23,26,27]}$. Participants stood in anatomical position during digitization to guarantee accurate bony landmark identification (see Table 1). The medial and lateral aspect of each joint was digitized and the midpoint of the two points was calculated to determine the joint center ${ }^{[21,23,26,27]}$. A link segment model was developed through digitization of joint centers for the ankle, knee, hip, shoulder, thoracic vertebrae 12 (T12) to lumbar vertebrae 1 (L1), and C7 to thoracic vertebrae 1 (T1). The spinal column was defined as the digitized space between the associated spinous processes, whereas the ankle and knee were defined as the midpoints of the digitized medial and lateral malleoli, medial and lateral femoral condyles, respectively. The shoulder and hip joint centers were estimated using the rotation method. This method of calculating a joint center has been reported as providing accurate positional data ${ }^{[28,29]}$. The shoulder joint center was calculated from the rotation between the humerus relative to the scapula and the hip joint center was from the rotation of the femur relative to the pelvis. The rotation method was implemented with the joint stabilized and then passively moved in 10 positions in a small circular pattern ${ }^{[29]}$. The variation in the measurement of the joint center had to have a root mean square error of less than $0.003 \mathrm{~m}$ in order to be accepted.

The collection rate for all kinematic data describing the position and orientation of electromagnetic sensors was set at $144 \mathrm{~Hz}^{[21,23,2430,31]}$. Raw data were independently filtered along each global axis using a $4^{\text {th }}$ order Butterworth filter with a cutoff frequency of $13.4 \mathrm{~Hz}$. Force plate data were sampled at a rate of 1,000 Hz. Raw data regarding sensor orientation 
and position were transformed to locally based coordinate systems for each of the respective body segments. Two points described the longitudinal axis of each segment and the third point defined the plane of the segment ${ }^{[26]}$. The second axis was perpendicular to the plane and the third axis was defined as perpendicular to the first and second axes. The world axis was defined as the $y$-axis in the vertical direction, horizontal and to the right of $y$ was the $x$-axis, and posterior was the Z-axis ${ }^{[21,23,2430,31]}$. Euler angle decomposition sequences were used to describe both the position and orientation of the body segments ${ }^{[21,23,2430,31]}$ (see Table 2).

Table 1. Description of the trunk and upper extremity bony landmarks palpated and digitized to create a skeletal model of each participant

\begin{tabular}{ll}
\hline Bony Landmarks & Digitized Bony Processes \\
\hline Trunk & \\
Seventh Cervical Vertebra [C7] & C7 spinous process \\
Thoracic Vertebra $12[\mathrm{~T} 12]$ & T12 spinous process \\
Eighth Thoracic Vertebra [T8] & T8 spinous process \\
Suprasternal Notch & Most cranial aspect of sternum \\
Xiphoid Process & Most distal aspect of sternum \\
Humerus & \\
Medial Epicondyle & Medial aspect of humeral epicondyle \\
Lateral Epicondyle & Lateral aspect of humeral epicondyle \\
Forearm & \\
Radial Styloid Process & Lateral aspect of radial styloid \\
Ulnar Styloid Process & Medial aspect of ulnar styloid \\
\hline
\end{tabular}

Table 2. Angle orientation decomposition sequences

\begin{tabular}{lll}
\hline \multicolumn{1}{l}{ Segment } & Axis of Rotation & Angle \\
\hline Trunk & & \\
Rotation 1 & $\mathrm{Z}$ & Flexion[-]/Extension[+] \\
Rotation 2 & $\mathrm{X}^{*}$ & Left Lateral Tilt[-]/Right Lateral Tilt[+] \\
Rotation 3 & $\mathrm{Y}^{\#}$ & Right Rotation[+]/Left Rotation[-] \\
Shoulder & & \\
Rotation 1 & $\mathrm{Y}$ & Humeral Plane of Elevation $[0=$ Abduction; 90=Flexion] \\
Rotation 2 & $\mathrm{X}^{*}$ & Humeral Elevation \\
Rotation 3 & $\mathrm{Y}^{\#}$ & Shoulder Internal Rotation[+]/Shoulder External Rotation[-] \\
Elbow & & \\
Rotation 1 & $\mathrm{Z}$ & Flexion[+]/Hyperextension[-] \\
Rotation 2 & $\mathrm{X}^{*}$ & Carrying Angle \\
Rotation 3 & $\mathrm{Y}^{\#}$ & Pronation[+]/Supination[-] \\
\hline
\end{tabular}

Note. ${ }^{*}$ and ${ }^{\#}$ represent previously rotated axes due to the rotation of the local coordinate system resulting in all axes within that system being rotated. Rotation about $\mathrm{X}$ axis also results in rotation of both $\mathrm{Y}$ and $\mathrm{Z}$ axes resulting in a new system of $\mathrm{X}^{*}, \mathrm{Y}^{*}, \mathrm{Z}^{*}$. Subsequent rotation are then about those axes.

\subsection{Throwing protocol}

Following digitization, participants were allotted an unlimited time to warm-up and become familiar with the testing protocols. Once each participant deemed himself ready, the testing protocols began. Participants performed five maximal effort jump shots, from a distance of $8 \mathrm{~m}$, using an International Handball Federation (IHF) size 3 team handball ${ }^{[32-34]}$. In 
order for a trial to count as a vertical jump throw the horizontal distance between takeoff and landing could not exceed $2 \mathrm{~m}^{[35]}$. Additionally, only accurate shots that hit the center of a $1 \times 1 \mathrm{~m}^{2}$ target at a height of $1.75 \mathrm{~m}$ were saved ${ }^{[32-34]}$. The number of shots required to perform 5 shots accurately were recorded to determine the shot accuracy percentage ${ }^{[36]}$.

\subsection{Aerobic fatigue protocol}

The fatiguing protocol was participant specific based on each participants recorded maximal oxygen consumption $\left(\mathrm{VO}_{2} \mathrm{max}\right)$. The $\mathrm{VO}_{2}$ max testing occurred a minimum of 2 weeks prior to the implementation of the fatiguing protocol. The $\mathrm{VO}_{2}$ max testing used a standard testing protocol that consisted of the following: 5 minute easy sub-maximal run ( 2 minute warm up, 3 minute steady state); a three minute moderate sub-maximal run (steady state); three minute fast sub-maximal run (steady state); incremental $2 \%$ increases in grade until participant volitionally quit. The three sub-maximal levels provided the oxygen cost, heart rate, and workload relationships. The incremental stages culminated in a maximal heart rate and a maximal $\mathrm{VO}_{2}$ if the testing procedure met two of the following four criterion: 1) Volitional fatigue; 2) a $\mathrm{VO}_{2}$ plateau despite an increase in workload; 3) and resting expiratory ratio (RER) values of 1.15 or higher; and/or 4) maximum heart rate within \pm 12 beats of age predicted maximum. Based on the $\mathrm{VO}_{2}$ max testing, the workload (individually determined) that elicited a heart rate that was $80 \%$ of maximal was used for the fatigue testing protocol. The $80 \%$ work intensity was chosen based on average heart rate data (unpublished lab data) observed during team handball match play. Participants were instructed to run as long as they could (time to exhaustion) on a treadmill at a speed that corresponded with $80 \%$ of their heart rate maximum, as determined by the $\mathrm{VO}_{2}$ max testing, for the aerobic fatiguing protocol. During the fatiguing protocol, the Borg rating of perceived exertion (RPE) scale was used to assess the participant's perception of fatigue at each interval of the testing protocol ${ }^{[37,38]}$. Heart rate was recorded using a Polar heart rate monitor was utilized throughout testing. Immediately following the fatiguing protocol the participants performed 5 successful jump shots that met the previously established criteria.

\subsection{Experimental design}

The throwing motion was divided into the events of stride foot contact (FC), maximum shoulder external rotation (MER), ball release (BR), and maximum shoulder internal rotation (MIR) (see Figure 2). All kinematic data for this study were reduced using MotionMonitor ${ }^{\mathrm{TM}}$ (Innovative Sports Training, Chicago, IL) software. All five jump shot trial data were compiled and analyzed to limit variability between the trials. Statistical analyses were performed using SPSS software (version 20.0; SPSS Inc., Chicago, IL, USA), with an alpha level set a priori at $P \leq .05$. All data were compiled in a spreadsheet in Microsoft Excel in preparation for statistical analysis. Next, a within subjects repeated measures ANOVA was employed to determine if jump shot kinematics were significantly different following the fatiguing protocol.

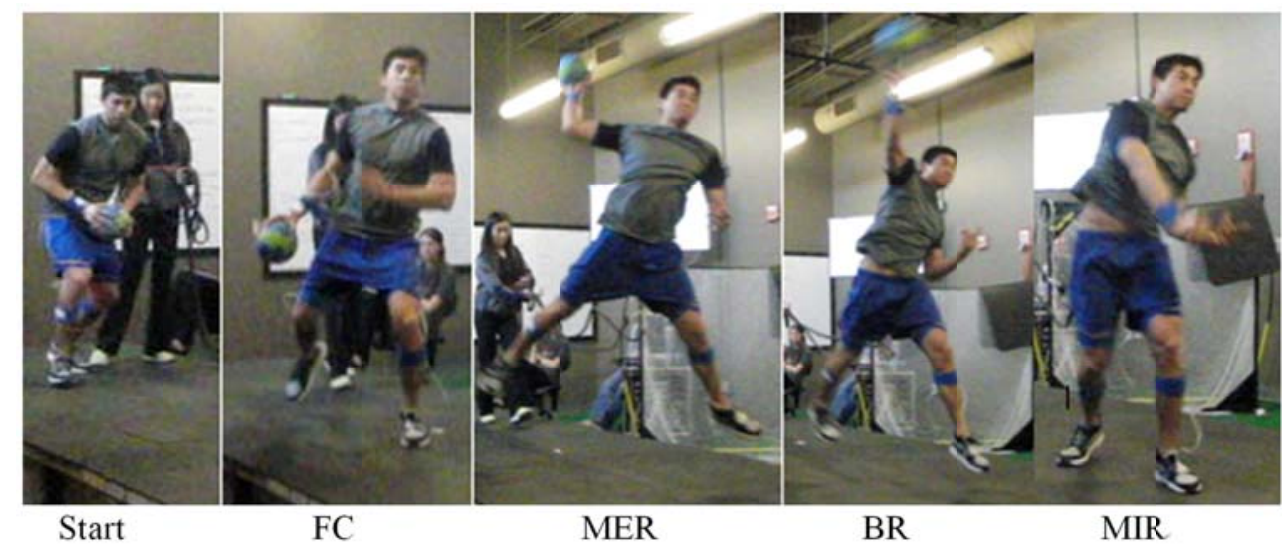

Figure 2. Events of a team handball jump shot 


\section{Results}

The mean throwing warm-up time for this study was $4.88 \pm 1.58$ minutes and each participant was allotted a three-minute running warm-up on the treadmill at $5.5 \mathrm{mph}$. The mean time to reach aerobic fatigue was $28.49 \pm 13.92$ minutes. Mean ball speed across the pre fatigue trials was $41.96 \pm 3.02 \mathrm{mph}$ and the speed was to $41.96 \pm 3.04 \mathrm{mph}(P=.99)$ following fatigue. Accuracy percentage in the pre fatigue trial was $54.49 \% \pm 13.15 \%$ and post aerobic fatigue accuracy percentage was $60.75 \% \pm 13.94 \%(P=.31)$.

Table 3. Jump shot upper extremity kinematics pre and post aerobic fatigue, mean (SD)

\begin{tabular}{|c|c|c|c|c|c|c|c|c|}
\hline & \multicolumn{4}{|c|}{ Pre Fatigue } & \multicolumn{4}{|c|}{ Post Fatigue } \\
\hline & FC & MER & BR & MIR & FC & MER & BR & MIR \\
\hline $\begin{array}{l}\text { Shoulder Plane of } \\
\text { Elevation }\left({ }^{\circ}\right)\end{array}$ & $\begin{array}{l}1.27 \\
(12.77)\end{array}$ & $\begin{array}{l}5.92 \\
(13.56)\end{array}$ & $\begin{array}{l}14.16 \\
(17.30)\end{array}$ & $\begin{array}{l}28.78 \\
(27.04)\end{array}$ & $\begin{array}{l}-6.23 \\
(22.34)\end{array}$ & $\begin{array}{l}1.91 \\
(14.65)\end{array}$ & $\begin{array}{l}10.39 \\
(18.15)\end{array}$ & $\begin{array}{l}25.77 \\
(28.20)\end{array}$ \\
\hline Shoulder Elevation $\left(^{\circ}\right)$ & $\begin{array}{l}24.69 \\
(9.64)\end{array}$ & $\begin{array}{l}95.38 \\
(8.68)\end{array}$ & $\begin{array}{l}81.41 \\
(9.40)\end{array}$ & $\begin{array}{l}80.01 \\
(12.19)\end{array}$ & $\begin{array}{l}24.87 \\
(9.21)\end{array}$ & $\begin{array}{l}92.21 \\
(12.84)\end{array}$ & $\begin{array}{l}77.67 \\
(11.43)\end{array}$ & $\begin{array}{l}81.69 \\
(11.31)\end{array}$ \\
\hline Shoulder Rotation $\left({ }^{\circ}\right)$ & $\begin{array}{l}25.60 \\
(19.09)\end{array}$ & $\begin{array}{l}-76.55 \\
(13.22)\end{array}$ & $\begin{array}{l}-53.92 \\
(8.94)\end{array}$ & $\begin{array}{l}-1.95 \\
(16.42)\end{array}$ & $\begin{array}{l}30.06 \\
(28.62)\end{array}$ & $\begin{array}{l}-73.15 \\
(15.61)\end{array}$ & $\begin{array}{l}-54.28 \\
(10.56)\end{array}$ & $\begin{array}{l}-0.85 \\
(20.23)\end{array}$ \\
\hline $\begin{array}{l}\text { Scapula IR/ER } \\
\text { Rotation }\left({ }^{\circ}\right)\end{array}$ & $\begin{array}{l}6.09 \\
(7.77)\end{array}$ & $\begin{array}{l}-19.96 \\
(5.76)\end{array}$ & $\begin{array}{l}-3.75 \\
(9.75)\end{array}$ & $\begin{array}{l}7.20 \\
(16.35)\end{array}$ & $\begin{array}{l}-3.98 \\
(9.93)\end{array}$ & $\begin{array}{l}-22.66 \\
(9.60)\end{array}$ & $\begin{array}{l}-8.19 \\
(9.87)\end{array}$ & $\begin{array}{l}3.28 \\
(15.57)\end{array}$ \\
\hline $\begin{array}{l}\text { Scapula Up/Down } \\
\text { Rotation }\left(^{\circ}\right)\end{array}$ & $\begin{array}{l}-7.01 \\
(5.33)\end{array}$ & $\begin{array}{l}-30.61 \\
(7.68)\end{array}$ & $\begin{array}{l}-21.63 \\
(9.87)\end{array}$ & $\begin{array}{l}-13.47 \\
(8.57)\end{array}$ & $\begin{array}{l}-6.74 \\
(4.90)\end{array}$ & $\begin{array}{l}-30.76 \\
(5.39)\end{array}$ & $\begin{array}{l}-20.29 \\
(5.50)\end{array}$ & $\begin{array}{l}-14.40 \\
(5.13)\end{array}$ \\
\hline $\begin{array}{l}\text { Scapula Ant/Post } \\
\text { Tilt }\left({ }^{\circ}\right)\end{array}$ & $\begin{array}{l}3.52 \\
(10.06)\end{array}$ & $\begin{array}{l}9.85 \\
(9.01)\end{array}$ & $\begin{array}{l}6.31 \\
(11.48)\end{array}$ & $\begin{array}{l}7.04 \\
(11.71)\end{array}$ & $\begin{array}{l}3.55 \\
(10.15)\end{array}$ & $\begin{array}{l}10.73 \\
(10.34)\end{array}$ & $\begin{array}{l}5.40 \\
(10.30)\end{array}$ & $\begin{array}{l}6.32 \\
(11.08)\end{array}$ \\
\hline Elbow Flexion $\left({ }^{\circ}\right)$ & $\begin{array}{l}93.32 \\
(21.20)\end{array}$ & $\begin{array}{l}95.83 \\
(20.95)\end{array}$ & $\begin{array}{l}54.03 \\
(9.44)\end{array}$ & $\begin{array}{l}48.99 \\
(12.40)\end{array}$ & $\begin{array}{l}96.08 \\
(18.47)\end{array}$ & $\begin{array}{l}96.18 \\
(9.06)\end{array}$ & $\begin{array}{l}50.07 \\
(34.33)\end{array}$ & $\begin{array}{l}45.22 \\
(12.97)\end{array}$ \\
\hline
\end{tabular}

Note. Humeral Plane of Elevation [0=Abduction; 90=Flexion]; Shoulder Internal Rotation [+]/Shoulder External Rotation [-]; Scapula Internal Rotation [+]/External Rotation [-]; Scapula Upward Rotation [-]/Downward Rotation [+]; Scapula Anterior Tilt [-]/Posterior Tilt [+]; Elbow Flexion [+]/Hyperextension [-].

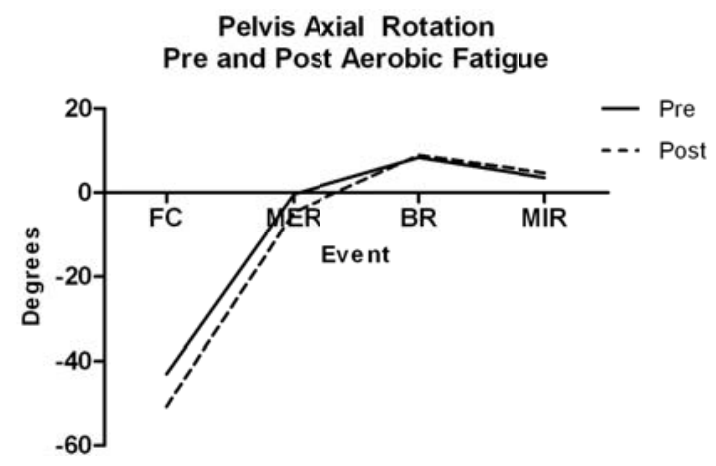

Figure 3. Pelvis axial rotation over time pre and post aerobic fatigue

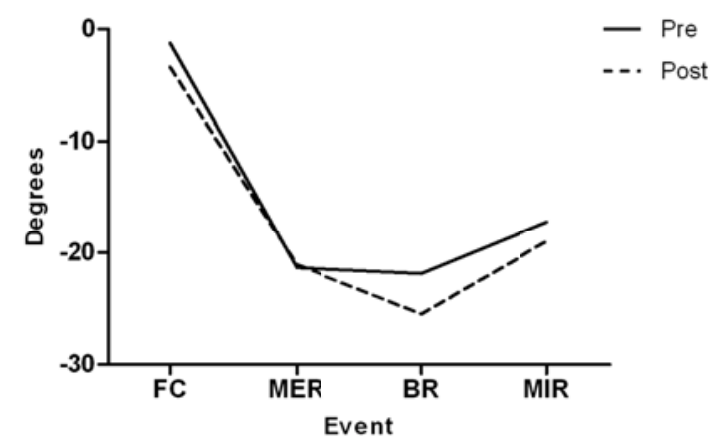

Figure 4. Pelvis lateral flexion over time pre and post aerobic fatigue, ${ }^{*} \mathrm{P}<.05$ at $\mathrm{BR}$ 
Upper extremity kinematic data are presented in Table 3. No significant kinematic differences were observed at the upper extremity following aerobic fatigue. Shoulder external rotation decreased from $-76.55^{\circ} \pm 13.22^{\circ}$ to $-73.15^{\circ} \pm 15.61^{\circ}$, at MER, following fatigue. Shoulder elevation and plane of elevation also decreased following aerobic fatigue. While not statistically significant, scapula external rotation increased at BR from $-3.75^{\circ} \pm 9.75^{\circ}$ to $-8.19^{\circ} \pm 9.87^{\circ}$ following fatigue. At MIR, the scapula was positioned in less internal rotation from $7.20^{\circ} \pm 16.35^{\circ}$ to $3.29^{\circ} \pm 15.57^{\circ}$. Significant pelvis and trunk kinematic differences were observed following the aerobic fatigue protocol (see Figures 3-7). For both the trunk $\left(\mathrm{F}_{6,54}=5.10 ; P<.01\right.$; power $\left.=0.99\right)$ and pelvis $\left(\mathrm{F}_{3,27}=14.47 ; P<.01\right.$; power $\left.=1.00\right)$ a three-way interaction of event $\times$ time $\times$ direction was observed. At FC of the jump shot, significant differences were observed for pelvis lateral flexion, pelvis rotation, and trunk flexion. The pelvis was positioned with greater lateral flexion to the contralateral side $\left(\mathrm{F}_{1,9}=5.48 ; P=.044\right.$; power $\left.=0.551\right)$ following aerobic fatigue $\left(-1.25^{\circ} \pm 3.41^{\circ}\right.$ to $\left.-3.39^{\circ} \pm 4.14^{\circ}\right)$ at $\mathrm{FC}$. Increased contralateral pelvis rotation was also observed in the jump shot following fatigue $\left(\mathrm{F}_{1,9}=14.18 ; P=.004\right.$; power $=0.917$; $-43.07^{\circ} \pm 12.92^{\circ}$ to $-50.79^{\circ} \pm 12.26^{\circ}$ ) at $\mathrm{FC}$. Pelvis lateral flexion towards the contralateral side was also significantly greater $\left(\mathrm{F}_{1,9}=7.34 ; \mathrm{P}=.024\right.$; power $\left.=0.675\right)$ at $\mathrm{BR}$ following aerobic fatigue $\left(-21.90^{\circ} \pm 5.99^{\circ}\right.$ to $\left.-25.55^{\circ} \pm 7.79^{\circ}\right)$. Additionally the trunk had significantly greater flexion at $\mathrm{FC}\left(\mathrm{F}_{1,9}=7.57 ; P=.022\right.$; power $\left.=0.688\right)$ following aerobic fatigue $\left(-16.16^{\circ} \pm 8.84^{\circ}\right)$ compared to when fatigue was not a factor in jump shot mechanics $\left(-13.83^{\circ} \pm 8.95^{\circ}\right)$. Trunk rotation significantly increased $\left(\mathrm{F}_{1,9}=6.64 ; P=.03\right.$; power $\left.=0.632\right)$ from $-6.80^{\circ} \pm 10.07^{\circ}$ to $-12.55^{\circ} \pm 10.97^{\circ}$ at $\mathrm{MER}$ following fatigue in this sample of team handball players.

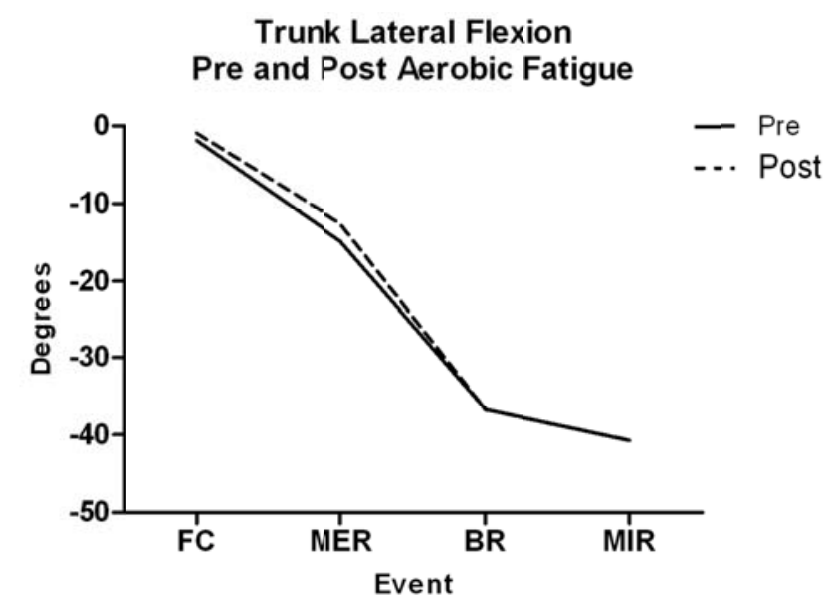

Figure 5. Trunk lateral flexion over time pre and post aerobic fatigue

\section{Trunk Flexion \\ Pre and Post Aerobic Fatigue}

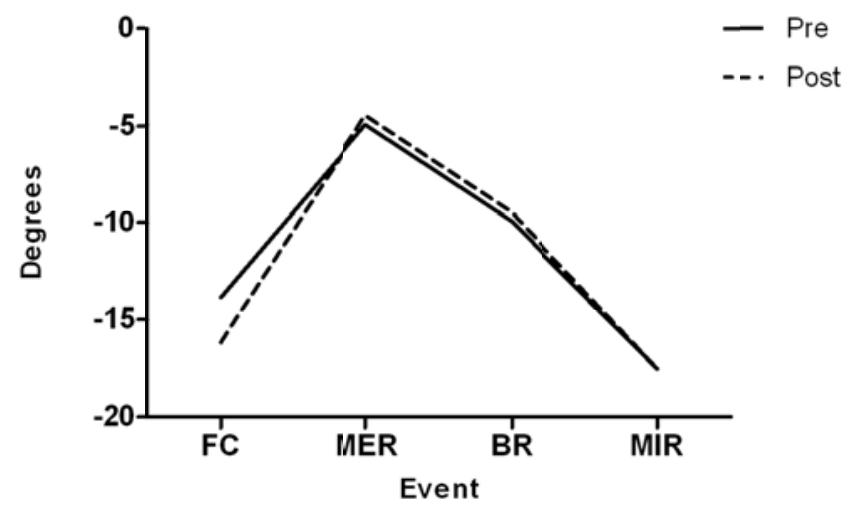

Figure 6. Trunk flexion over time pre and post aerobic fatigue, ${ }^{*} P<.05$ at FC 


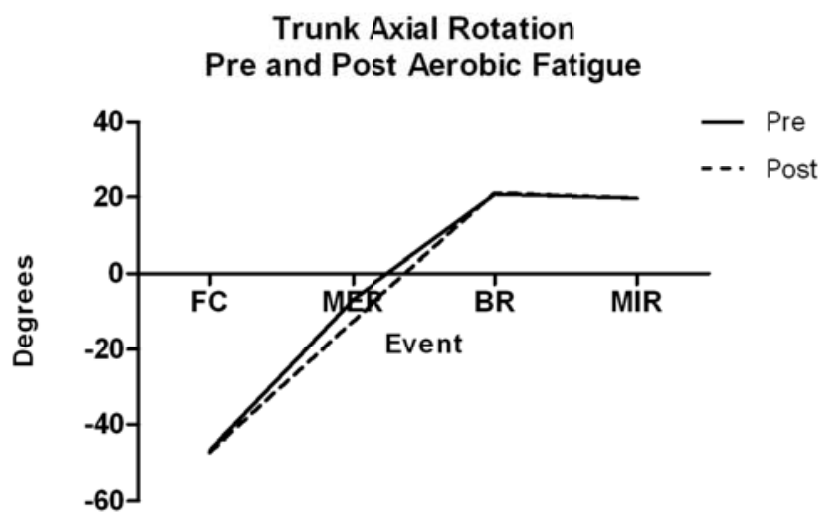

Figure 7. Trunk axial rotation over time pre and post aerobic fatigue, ${ }^{*} P<.05$ at MER

\section{Discussions}

This study provides meaningful data on the kinematics associated with the jump shot as well as how aerobic fatigue affects these kinematics. The results of this study are novel because this is the first study to examine the effects of fatigue on throwing mechanics in team handball players. While few statistically significant results were observed at the upper extremity the data provide further knowledge of shoulder kinematics and more specifically scapula kinematics during throwing. Proper scapula kinematics are paramount to the function of the shoulder during overhead movements ${ }^{[39]}$. Segmental sequencing and energy transfer, from the lower extremity to the upper extremity, is linked through the scapula and the transfer of energy is dependent on the stability of the scapula ${ }^{[40]}$. Decreased scapula stability may contribute to altered energy transfer from the lower extremity to the shoulder, elbow, wrist and hand. If energy transfer is altered then the distal segments may compensate to make up for the decreased energy, possibly contributing to upper extremity injury over time.

Scapula kinematics in youth baseball pitchers during the first and last innings of a simulated game have previously been examined by Oliver et al. ${ }^{[40]}$. It was reported that scapula kinematics did not significantly change following a simulated game. While scapula kinematics remained consistent prior to and following a simulated game, the current study provides valuable data on the movement of the scapula during throwing in team handball. Data, to the best of the authors' knowledge have never been reported in the literature. The upward rotation values observed in the current study are in agreement with the values reported by Oliver and Weimar (2014). During throwing the scapula should be in a position of external rotation, upward rotation, and posterior tilt at maximum external rotation to provide stability to the shoulder. External rotation of the scapula is vital, at maximum external rotation, because it enables a stable base for the shoulder as energy begins to be transferred through the scapula to the shoulder ${ }^{[41]}$. Once the throwing motion progresses the scapula quickly moves from external rotation to internal rotation. Inadequate internal rotation of the scapula as the throw progresses into the follow-through phase increases the forces about the shoulder whereas too much internal rotation can lead to impingement as the scapula rotates down and forward ${ }^{[41]}$. Furthermore, anterior and posterior tilt of the scapula also contributes to impingement as this motion directly affects the amount of subacromial space.

Due to the demands of the fatiguing protocol, it was expected that pelvis and trunk kinematics would be altered following fatigue more so than upper extremity kinematics. This hypothesis proved to be true following the fatigue protocol. The pelvis and trunk are pivotal segments in the kinetic chain and overall energy production during throwing as $51 \%$ of total kinetic energy is created by the legs, hip, and trunk ${ }^{[41]}$. Because a large amount of energy is generated and transferred from the lower extremity through the structures to the upper extremity, kinematic changes to the trunk following fatigue may have implications at the distal segments of the kinetic chain. Following fatigue trunk flexion significantly increased 
$(P=.022)$ at foot contact to $-16.16^{\circ} \pm 8.84^{\circ}$ compared to $-13.83^{\circ} \pm 8.95^{\circ}$. The increase in trunk flexion differs from what has been reported in baseball pitchers as they approach fatigue in a simulated game. Escamilla et al. ${ }^{[42]}$ observed a decrease in trunk flexion at ball release $34^{\circ} \pm 12^{\circ}$ to $29^{\circ} \pm 11^{\circ}$ in collegiate pitchers. It has previously been reported in baseball pitching that as trunk flexion increases, ball velocity also increases and as trunk flexion decreases, ball velocity also tends to decrease ${ }^{[43]}$. This trend does not seem to be the case in the team handball jump shot because ball velocity decreased even though there was an increase in trunk flexion in the current study. In addition to the increase is trunk flexion, the trunk had less lateral flexion at maximum external rotation following aerobic fatigue. These results indicate that the trunk was in a more neutral, upright position during the throw following fatigue. This decrease in trunk lateral flexion may have occurred as the participants attempted to maintain their center of gravity between the base of support. Following the completion of the aerobic fatigue protocol trunk rotation significantly increased $(P=.03)$ from $-6.80^{\circ} \pm$ $10.07^{\circ}$ to $-12.55^{\circ} \pm 10.97^{\circ}$ at maximum external rotation indicating that the participants were rotated more to the non-throwing side, towards the target, once they were fatigued. Similar results were observed at the pelvis where increased rotation was also observed $\left(-43.07^{\circ} \pm 12.92^{\circ}\right.$ to $\left.-50.79^{\circ} \pm 12.26^{\circ}\right)$. The pelvis was positioned with greater lateral flexion to the non-throwing side following aerobic fatigue $\left(-1.25^{\circ} \pm 3.41^{\circ}\right.$ to $\left.-3.39^{\circ} \pm 4.14^{\circ} ; P=.044\right)$ at foot contact. Pelvis lateral flexion towards the non-throwing side was also significantly greater $(P=.024)$ at ball release following aerobic fatigue $\left(-21.90^{\circ} \pm 5.99^{\circ}\right.$ to $\left.-25.55^{\circ} \pm 7.79^{\circ}\right)$. It is evident that pelvis and trunk kinematics during the jump shot are altered by the examined aerobic fatiguing protocol however the role that these alterations play in performance and injury are not well understood. These alterations in trunk and pelvis kinematics may lead to decreased proximal stability and energy transfer to the upper extremity.

Although valuable data were obtained from this study it is important to note that limitations do exist. This study was performed in a controlled laboratory setting rather than a competition setting. Performing this study in a laboratory environment makes it difficult to determine if the results are indicative of a competitive setting. The participants did not have to take into account the actions of the defense and the goalie in the laboratory and these external factors could have significant influence on jump shot mechanics. A benefit of being in a controlled laboratory setting is that kinematic measures could easily be obtained and more accurate data could be collected compared to a competitive setting. Another limitation of this study was the variability in playing experience (1-8 years) of the participants that volunteered. Because of the variability in team handball playing experience it is possible that the observed differences following fatigue cannot be generalized to more experienced players. Regardless of the limitations that exist, this study is novel because it is the first study to examine the effects of fatigue on throwing performance in any sport. All of the previous studies in baseball players have implemented simulated games however fatigue indices were not tracked and the pitchers only threw a predetermined number of pitches ${ }^{[40,42]}$. Therefore the comparison of these results to that of the current study should be interpreted with caution as only the current study truly examined fatigue.

Future research should aim to develop an aerobic fatiguing protocol that more closely mimics the competitive demands of team handball in effort to better determine kinematic changes that may occur as a result of fatigue. A protocol that utilizes a combination of sprinting, change-of direction, lateral movements, and jogging may have a different effect on jump shot kinematics than the current protocol. Future research should also aim to examine injury prevalence and kinematics in a large sample of experienced team handball players to establish if relationships between throwing kinematics and injury exist. If relationships between these variables do in fact exist then further examining the effects of fatigue can have important implications on the development and implementation of injury prevention protocols in team handball players. Future research should also include the examination of muscle activation and firing patterns during the jump shot to better understand the role of fatigue.

\section{Conclusions}

The pelvis was positioned with greater lateral flexion to the contralateral side and increased contralateral pelvis rotation was observed. Pelvis lateral flexion towards the contralateral side was also significantly greater at ball release following 
fatigue and trunk rotation significantly increased at maximum external rotation. The differences that were observed following aerobic fatigue occurred predominately at the pelvis and trunk segments. Due to altered mechanics being observed following fatigue it may be necessary to focus training and rehabilitation on strengthening the stabilizing musculature of these segments in effort to prevent kinematics alteration from occurring.

\section{References}

[1] Madigan ML, Pidcoe PE. Changes in landing biomechanics during a fatiguing landing activity. J Electromyogr Kinesiol. 2003; 13(5): 491-8. http://dx.doi.org/10.1016/S1050-6411(03)00037-3

[2] Small K, McNaughton L, Greig M, et al. The effects of multidirectional soccer-specific fatigue on markers of hamstring injury risk. J Sci Med Sport. 2010; 13(1): 120-5. PMid:18976956. http://dx.doi.org/10.1016/j.jsams.2008.08.005

[3] Sanna G, O'Connor KM. Fatigue-related changes in stance leg mechanics during sidestep cutting maneuvers. Clin Biomech. 2008; 23(7): 946-54. PMid:18468745. http://dx.doi.org/10.1016/j.clinbiomech.2008.03.065

[4] Bigland-Ritchie B, Woods JJ. Changes in muscle contractile properties and neural control during human muscular fatigue. Muscle Nerve. 1984; 7(9): 691-9. PMid:6100456. http://dx.doi.org/10.1002/mus.880070902

[5] Vollestad NK. Measurement of human muscle fatigue. J Neurosci. Methods. 1997; 74: 219-27. http://dx.doi.org/10.1016/S0165-0270(97)02251-6

[6] Tripp BL, Yochem EM, Uhl TL. Recovery of upper extremity sensorimotor system acuity in baseball athletes after a throwing-fatigue protocol. Jof Athl Train. 2007; 42(4): 452-7. PMid:18174932.

[7] Tripp BL, Yochem EM, Uhl TL. Functional fatigue and upper extremity sensorimotor system acuity in baseball athletes. J Athl Train. 2007; 42(1): 90-9. PMid:17597949.

[8] Tripp BL, Boswell L, Gansneder BM, et al. Functional fatigue decreases 3-dimensional multijoint position reproduction acuity in the overhead throwing athlete. J of Athl Train. 2004; 39(4): 316-20. PMid:15592603.

[9] Radin EL. Role of muscles in protecting athletes from injury. Acta Medica Scandinavica Supplement. 1986; 711 : $143-7$. http://dx.doi.org/10.1111/j.0954-6820.1986.tb08943.x

[10] Vuillerme N, Sporbert C, Pinsault N. Postural adaptation to unilateral hip muscle fatigue during human bipedal standing. Gait Posture. 2009; 30(1): 122-5. PMid:19403311. http://dx.doi.org/10.1016/j.gaitpost.2009.03.004

[11] Zech A, Steib S, Hentschke C, et al. Effects of localized and general fatigue on static and dynamic postural control in male team handball athletes. J Strength Cond Res. 2012; 26(4): 1162-8. PMid:22446681. http://dx.doi.org/10.1519/JSC.0b013e31822dfbbb

[12] Springer BK, Pincivero DM. The effects of localized muscle and whole-body fatigue on single-leg balance between healthy men and women. Gait Posture. 2009; 30(1): 50-4. PMid:19327999. http://dx.doi.org/10.1016/j.gaitpost.2009.02.014

[13] Russell M, Benton D, Kingsley M. The effects of fatigue on soccer skills performed during a match simulation. Int J Sports Physiol Perform. 2011; 6: 221-33. PMid:21725107.

[14] Wilkins JC, Valovich McLeod TC, Perrin DH, et al. Performance on the Balance Error Scoring System decreases after fatigue. J of Athl Train. 2004; 39(2): 156-61. PMid:15173867.

[15] Cortes N, Greska E, Kollock R, et al. Changes in lower extremity biomechanics due to a short-term fatigue protocol. J Athl Train. 2013; 48(3): 306-13. PMid:23675789. http://dx.doi.org/10.4085/1062-6050-48.2.03

[16] Cortes N, Quammen D, Lucci S, et al. A functional agility short-term fatigue protocol changes lower extremity mechanics. J Sports Sci. 2012; 30(8): 797-805. PMid:22424559. http://dx.doi.org/10.1080/02640414.2012.671528

[17] Ludwig PM, Cook TM. Alterations in shoulder kinematics and associated muscle activation in people with symptoms of shoulder impingement. J of Phys Ther. 2000; 80: 276-91.

[18] Day J, Murdoch D, Dumas G. Calibration of position and angular data from a magnetic tracking device. J Biomech. 2000; 33: 1039-45. http://dx.doi.org/10.1016/S0021-9290(00)00044-0

[19] Meskers CGM, Fraterman H, van der Helm FCT, et al. Calibration of the "Flock of Birds" electromagnetic tracking device and its application in shoulder motion studies. J Biomech. 1999; 32: 629-33. http://dx.doi.org/10.1016/S0021-9290(99)00011-1

[20] Perie D, Tate AJ, Cheng PL, et al. Evaluation and calibration of an electromagnetic tracking device for biomechanical analysis of lifting task. J Biomech. 2002; 35: 293-7. http://dx.doi.org/10.1016/S0021-9290(01)00188-9

[21] Plummer HA, Oliver GD. The relationship between gluteal muscle activation and throwing kinematics in baseball and softball catchers. J Strength Cond Res. 2013; 28(1): 87-96. PMid:23591952. http://dx.doi.org/10.1519/JSC.0b013e318295d80f

[22] Plummer HA, Oliver GD. Quantitative analysis of the kinematics of the overhead lacrosse shot in youth. International Biomechanics. 2015; 2(1): 29-35. http://dx.doi.org/10.1080/23335432.2015.1017608 
[23] Plummer HA, Oliver GD. Quantitative analysis of kinematics and kinetics of catchers throwing to second base. J Sports Sci. 2013; 31(10): 1108-16. PMid:23419054. http://dx.doi.org/10.1080/02640414.2013.770907

[24] Oliver GD, Plummer H. Ground reaction forces, kinematics, and muscle activations during the windmill softball pitch. J Sports Sci. 2011; 29(10): 1071-7. PMid:21678150. http://dx.doi.org/10.1080/02640414.2011.576692

[25] Keeley DW, Oliver GD, Dougherty CP. Shoulder kinematics during pitching: comparing the slide step and traditional stretch deliveries. Human movement Science. 2012; 31(5): 1191-9. PMid:22487194. http://dx.doi.org/10.1016/j.humov.2011.12.008

[26] Oliver GD. Relationship between gluteal muscle activation and upper extremity kinematics and kinetics in softball position players. Med Biol Eng Comput. 2013. PMid:23519517.

[27] $\mathrm{Wu} \mathrm{G}$, van der Helm FCT, Veeger HEJ, et al. ISB recommendation on definitions of joint coordinate systems of various joints for the reporting of human joint motion-Part II: shoulder, elbow, wrist and hand. J Biomech. 2005; 38(5): 981-92. PMid:15844264. http://dx.doi.org/10.1016/j.jbiomech.2004.05.042

[28] Veeger HEJ. The position of the rotation center of the glenohumeral joint. J Biomech. 2000; 33: 1711-5. http://dx.doi.org/10.1016/S0021-9290(00)00141-X

[29] Huang YH, Wu TY, Learman KE, et al. A comparison of throwing kinematics between youth baseball players with and without a history of medial elbow pain. Chin J Physiol. 2010; 53(3): 160-6. PMid:21793324. http://dx.doi.org/10.4077/CJP.2010.AMK026

[30] Oliver GD, Keeley DW. Gluteal muscle group activation and its relationship with pelvis and torso kinematics in high-school baseball pitchers. J Strength Cond Res. 2010; 24(11): 3015-22. PMid:20664365. http://dx.doi.org/10.1519/JSC.0b013e3181c865ce

[31] Oliver GD, Keeley DW. Pelvis and torso kinematics and their relationship to shoulder kinematics in high-school baseball pitchers. J Strength Cond Res. 2010; 24(12): 3241-6. PMid:20703168. http://dx.doi.org/10.1519/JSC.0b013e3181cc22de

[32] Wagner H, Pfusterschmied J, Klous M, et al. Movement variability and skill level of various throwing techniques. Human movement Science. 2012; 31(1): 78-90. PMid:21835479. http://dx.doi.org/10.1016/j.humov.2011.05.005

[33] Wagner H, Buchecker M, Duvillard SPv, et al. Kinematic comparison of team handball throwing with two different arm positions. Int J Sports Physiol Perform. 2010; 5: 469-83. PMid:21266732.

[34] Wagner H, Muller E. The effects of differential and variable training on the quality parameters of a handball throw. Sports Biomech. 2008; 7(1): 54-71. PMid:18341136. http://dx.doi.org/10.1080/14763140701689822

[35] Wagner H, Buchecker M, von Duvillard SP, et al. Kinematic description of elite vs. low level players in team-handball jump throw. J Sports Sci Med. 2010; 9: 15-23. PMid:24149381.

[36] Wagner H, Pfusterschmied J, von Duvillard SP, et al. Performance and kinematics of various throwing techniques in team-handball. J Sports Sci Med. 2011; 10: 73-80. PMid:24149298.

[37] Benjaminse A, Habu A, Sell TC, et al. Fatigue alters lower extremity kinematics during a single-leg stop-jump task. Knee Surg Sports Traumatol Arthrosc. 2008; 16(4): 400-7. PMid:18026933. http://dx.doi.org/10.1007/s00167-007-0432-7

[38] Miller GS, Dougherty PJ, Green JS, et al. Comparison of cardiorespiratory responses of moderately trained men and women using two different treadmill protocols. J Strength Cond Res. 2007; 21(4): 1067-71. PMid:18076250.

[39] Laudner KG, Stanek JM, Meister K. Differences in scapular upward rotation between baseball pitchers and position players. Am J Sports Med. 2007; 35(12): 2091-5. PMid:17687122. http://dx.doi.org/10.1177/0363546507305098

[40] Oliver GD, Weimar W. Hip range of motion and scapula position in youth baseball pitching pre and post simulated game. J Sports Sci. 2015; 33(14): 1447-53. PMid:25529372. http://dx.doi.org/10.1080/02640414.2014.990493

[41] Kibler WB, Press J, Sciascia A. The role of core stability in athletic function. Sports Med. 2006; 36(3): 189-98. PMid:16526831. http://dx.doi.org/10.2165/00007256-200636030-00001

[42] Escamilla RF, Barrentine SW, Fleisig GS, et al. Pitching biomechanics as a pitcher approaches muscular fatigue during a simulated baseball game. Am J Sports Med. 2007; 35(1): 23-33. PMid:16973902. http://dx.doi.org/10.1177/0363546506293025

[43] Matsuo T, Escamilla RF, Fleisig GS, et al. Contributions of factors based on kinematic relationship of inter-subject variablity of baseball pitch velocity. J Appl Biomech. 2001; 17: 1-13. 